ANTONIO PRATELLI, M.S. ${ }^{1}$

E-mail: antonio.pratelli@ing.unipi.it

PIETRO LEANDRI, M.S. ${ }^{1}$

E-mail: pietro.leandri@ing.unipi.it

ROSARIA AIELLO, M.S. ${ }^{1}$

E-mail: aiello.sara91@gmail.com

REGINALD R. SOULEYRETTE, Ph.D. ${ }^{2}$

E-mail: souleyrette@uky.edu

${ }^{1}$ University of Pisa

Department of Civil and Industrial Engineering

Largo Lucio Lazzarino 2, 56122 Pisa, Italy

${ }^{2}$ University of Kentucky

Department of Civil Engineering

Oliver H. Raymond Civil Engineering Building 161A,

40506 Lexington - KY, U.S.A.
Traffic Engineering Original Scientific Paper Submitted: 25 Mar. 2020 Accepted: 16 Feb. 2021

\title{
INTERSECTION REDESIGN FOR NETWORK RESILIENCE AND SAFETY
}

\begin{abstract}
This paper describes a procedure for improving the resilience of roadway networks. A methodology is outlined that develops a time-dependent and performance-based resilience index. This methodology was applied to an Italian road, with the aim of optimizing intersections that are critical due to inadequate baseline capacity. The methodology uses a calibrated microscopic traffic model (using Aimsun ${ }^{\mathrm{TM}}$ ) whereby average delay at intersection approaches are estimated by an analytical model. From the simulation, average speed over time is obtained for each approach. These values in turn are used as inputs for calculating each intersection's resilience index. The procedure allows the identification of less resilient intersections, and provides design solutions for each of them. Lastly, a safety assessment is tested for one of the intersections.
\end{abstract}

\section{KEYWORDS}

resilience; resilience of road facilities; traffic system resilience attitude index and metric; urban local network micro-simulation.

\section{INTRODUCTION}

Ground transportation systems are essential for the mobility of people, goods and for the development of services; therefore, resilient systems should become a top priority [1].

The word resilience comes from the Latin verb "resiliere", which means rebound or spring back to a previous state; this concept was introduced for the first time by Holling in an ecological context [1], who wrote: "Resilience implies the persistence of system to external influences and their ability to absorb disturbance and adapt their dynamics". Since then, a significant number of studies has focused on various domains, including transportation engineering. Though there may be different interpretations of transport resilience, most are based on the idea that "resilience is the system's ability to resist a shock and restore its performance following damage and/ or collapse". It is important to know that the attribute systems should be resilient. Bruneau and Tierney [2] introduced a framework indicating that resilience can be associated with four such attributes: robustness, redundancy, resourcefulness, and rapidity. These four properties are also known as the 4Rs of resilience. In ground transportation, robustness reflects the ability of the network and its elements to resist the impact of a disruptive event without significant system degradation. Redundancy is the extent to which routes and/or transportation modal alternatives can be employed if some components are damaged. Resources relate to the availability of capital, labor, and authority to restore functionality. Finally, rapidity is the ability to restore system performance in a timely manner [3].

Over time, road infrastructures are becoming more vulnerable to the impact of a disturbing event; once a disruption occurs, network performance decreases considerably in a short period of time up to traffic congestion [1]. This paper first presents a methodology for determining the resilience to be achieved by redesign of existing components (i.e., intersections). More specifically, it is recommended 
to convert and adapt roundabouts, which would not only increase resilience but have the added benefit of improving safety. The suggested procedure uses dynamic methods to analyze the resilience of a network in both its present and redesigned states. It then uses a simulation software (i.e., Aimsun ${ }^{\mathrm{TM}}$ ) to obtain the "resilience indices" for proposed intersection redesigns.

\section{RESILIENCE METRIC}

A road network's resilience may be defined by computing various measures. Such metrics can consider the graph of the transport network and its traffic flow, thus evaluating the resilience in a comprehensive and objective way [4]. In general, resilience is identified by the degradation of system quality over time according to the three-stage model (Figure 1) [5]. This model considers three stages of resilience: (1) disaster prevention, (2) damage propagation, and (3) assessment and recovery. The first stage is the period prior to the initial failure and it determines the resistant capacity of the system. This stage is followed by damage propagation, wherein the system performance reaches a minimum value. Finally, the assessment and recovery stage includes the period in which information is collected and normal performance is restored.

The loss of resilience (LOR), which occurs from the moment the disaster begins until complete recovery of system performance, is used to quantify resilience. LOR is defined as follows:

$$
L O R=\int_{t_{0}}^{t_{2}}[100-Q(t)] d t
$$

where:

$Q(t)$ - the quality of the system over time, it is quantified by performance metric;

$t_{0} \quad$ - occurrence time of disruption;

$t_{2} \quad$ - completed time point of recovery.
The value of this indicator is equal to the shaded area in Figure 1 and referred to as the "resilience triangle". However, the impact of a disruptive event to a road system may also be represented by a "resilience trapezoid", in which the status of the network's functionality has reached $Q\left(t_{1}\right)$, and remains at $Q\left(t_{1}\right)$ for a time before its recovery begins [6].

Equation 1 represents a starting point for establishing a resilience index. Ouyang et al. (2012) [1] define Resilience Index $(R I)$ as the ratio of the area under the Actual Performance Curve $(A P)$ over that under the Target Performance Curve (TP) (Figure 2). The $A P$ represents the system under the disrupted condition, while the $T P$ is the curve that represents the system performance under normal conditions $\left(q_{0}\right)$ or a pre-established performance standard $\left(q^{*}\right)$. The Resilience Index is defined as follows:

$R I=\frac{\int_{t_{0}}^{t_{2}} A P(t) d t}{\int_{t_{0}}^{t_{2}} T P(t) d t}=\frac{\int_{t_{0}}^{t_{2}} A P(t) d t}{q^{*} \cdot t_{2}}$

The index varies between 0 and 1 . An $R I$ equal to 1 indicates a 100 percent resilient system, and it approaches 0 when $L O R$ values are high.

In one model, the predefined standards focus on the robustness and rapidity properties of the system, as $r^{*}\left(q_{0}-q^{*}\right)$ represents the maximum acceptable loss in the system performance, while $t^{*}$ represents the maximum acceptable time for recovery $[7,8]$. This model was applied to measure the resilience of a power transmission grid in Harris County, Texas when subject to random hurricane hazards.

An application specifically set up for ground transport systems is found in Nieves-Meléndez (2017) [7] and it involves some signalized intersections, but no roundabouts. Moreover, the road systems considered in [7] are characterized by relevant "locations" in the network, while the intervention

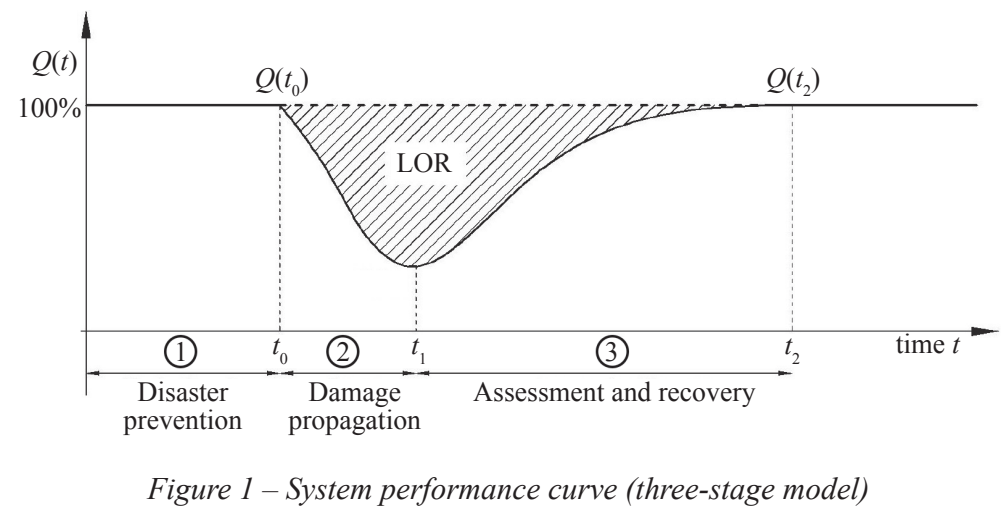




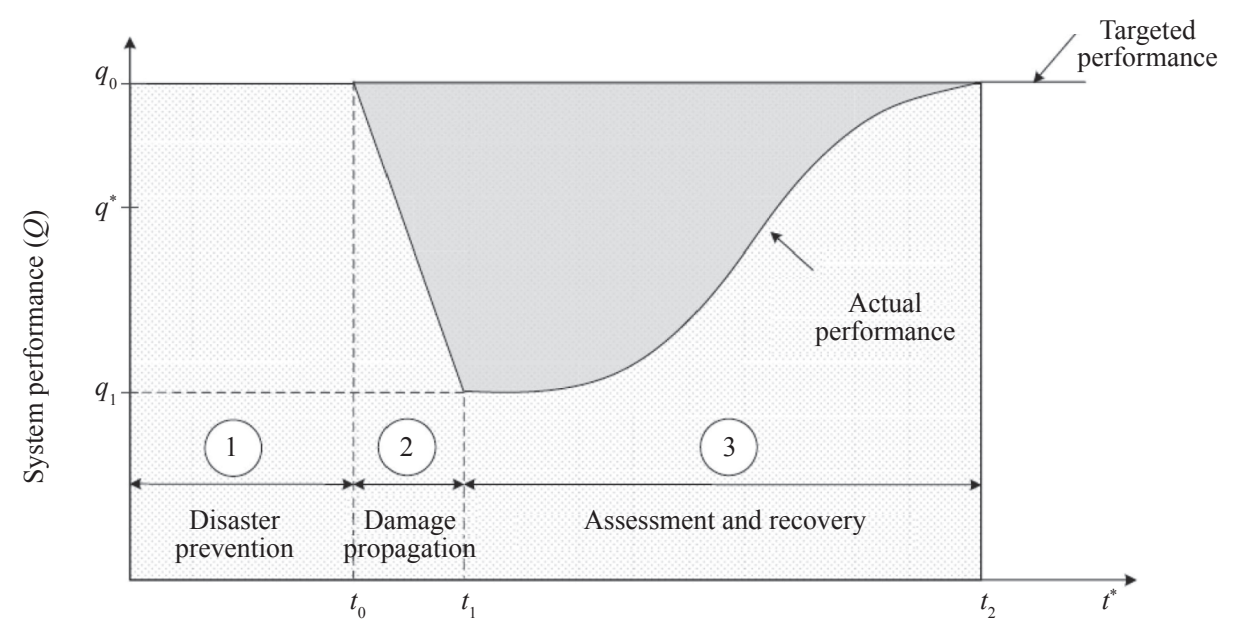

Figure 2 - Three-stage framework for measuring resilience (from Nieves-Meléndez M.E., 2007) [7]

strategies tested include ramp meters and the use of the shoulder lane. A traffic based pilot study for a small urban network was applied in [8] whereby the results obtained show that the deterministic approach is more suitable than the stochastic one.

To adapt resilience models to traffic-based applications, typical traffic congestion performance measures can be considered, such as speed, delay, travel time, and level of service, among others (FHWA, TRB) $[9,10]$. In $[7,8]$, average speed was selected as the parameter to measure the resilience of roads, since it depicts more closely the behavior of the resilience curves used to define the model. Therefore, Equation 2 is rewritten as:

$R I=\frac{\int_{t_{1}}^{t_{2}} v(t) d t}{v^{*} \cdot\left(t_{2}-t_{1}\right)}$

where:

$\left(t_{2}-t_{1}\right)=t^{*}-$ represents the standard of recovery time;

$v^{*} \quad-$ previously $q^{*}$, represents the vehicle average speed that meets the robustness standard $r^{*}$. There isn't a fixed value for $v^{*}:$ it depends on the examined road or intersection.

The pre-established performance standard is represented by speed limit of the road. The hypothesis was considered valid that the road network is considered resilient if the speed magnitude is within five percent of the speed limit (robustness standard $r^{*}$ ). Moreover, considering that the event duration was 60 minutes, a rapidity standard $\left(t^{*}\right)$ of 75 minutes was selected to allow 15 minutes for recovery after the peak disruption was concluded $[7,8]$. For the entire duration of the event, the network is loaded and a time interval of 15 minutes was chosen at the beginning to allow for adequate loading.

\section{PRINCIPLES OF THE NETWORK MICRO-SIMULATION AND METHODOLOGY}

The methodology outlined in this paper aims to optimize a road network in terms of resilience by identifying critical intersections (Figure 3). This procedure involves the setup of a microscopic traffic model using the simulation software Aimsun ${ }^{\mathrm{TM}}$ (Transport Simulation System, TSS) in which network scenarios are built, flows are represented, and the model is defined according to a process described below.

Intrusions to consider when modeling traffic include the seven factors that cause traffic congestion: traffic incidents, work zones, weather, demand fluctuations, special events, traffic control devices, and inadequate baseline capacity [7]. For the purpose of this research, the resilience of the road network has been tested with respect to its baseline capacity. This type of criticality is considered within a road's normal operating conditions. Therefore, it was assumed that the sections that appear heavily congested are such only due to inadequate baseline capacity and not due to other impediments. Modeling and simulation of this scenario was conducted to analyze the typical traffic demand of the artery in question.

Using this configuration, the Aimsun ${ }^{\mathrm{TM}}$ simulation gives the average speed over time for every approach to network intersections. The duration of the analysis was 1 hour (from 7:45 to 8:45) divided into 15-minute intervals. From the Aimsun ${ }^{\mathrm{TM}}$ output, 
the methods of Ouyang et al. (2012) (Equation 3) are used to compute the values of the resilience index $(R I)$ for each approach [1]. Next, the intersection $R I$ index was calculated from the weighted average of the approach $R I \mathrm{~s}$, using resilience losses $(L O R)$ obtained from the speed-time diagrams of the approaches involved as weights. Finally, the resilience value of the network was determined as the arithmetic mean of $R I$ s for each intersection.

For the purpose of increasing the arterial resilience, intervention is suggested for intersections with the $R I$ lower than 0.70 , as it has been found that negligible improvements are obtained for higher values [7]. The conceptual framework shown (Figure 3) can be used to examine the resilience of a road network at a microscopic level under different scenarios or to predict the impact of various interruptions and interventions on the system. This procedure can be applied to other types of networks although the details of each step will differ with the type of transport system considered. In the traffic modelization, all vehicles have been converted into equivalent passenger cars.

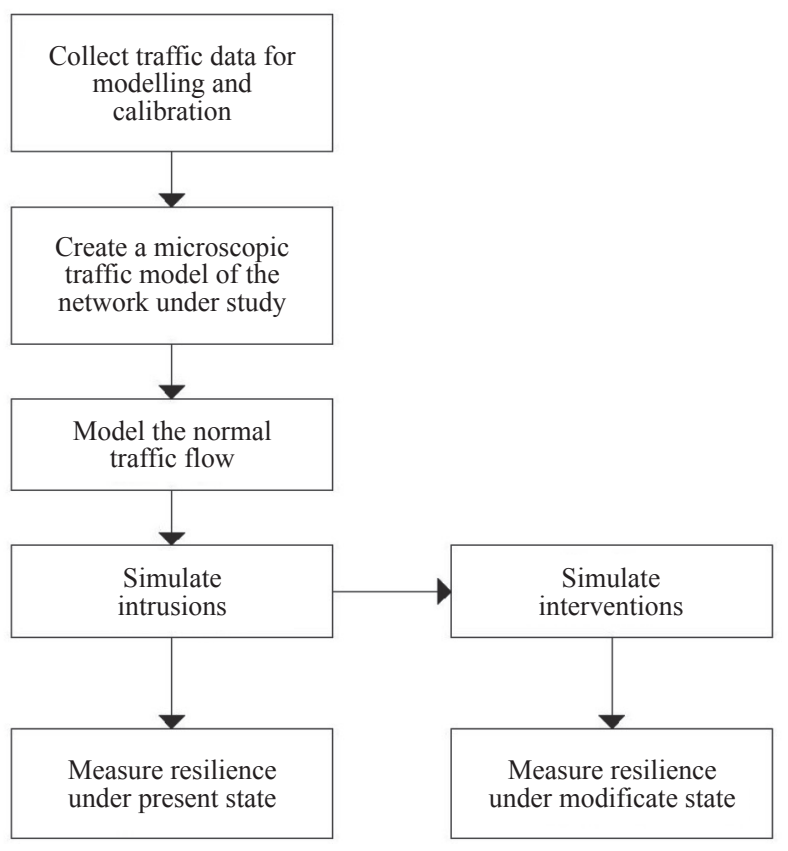

Figure 3 - Flowchart of the methodology for measuring the resilience of a system under normal conditions

\subsection{Model definition}

Aimsun $^{\mathrm{TM}}$ creates general models that must be adapted to the situation examined by means of an appropriate calibration process (Figure 4). The default parameters of Aimsun ${ }^{\mathrm{TM}}$ have been used in this study, which have been calibrated for traffic conditions, probably in Spain.

Delay time is calculated using the Highway Capacity Manual 2016 (HCM6th) Equation 4:

$d=\frac{3600}{c}+$

$+900 T\left[x-1+\sqrt{(x-1)^{2}+\frac{\frac{3600}{c} x}{450 T}}\right]+5 \min [x, 1]$

where:

$d$-delay time at entry [s/pce]

$c$ - capacity at entry $[\mathrm{pce} / \mathrm{h}]$

$x$ - saturation index (Entry flow/Entry capacity)

$T$ - period of reference ( $T$ is 0.25 for a 15 -minute

traffic analysis, and 1 is 1 -hour analysis).

The approach delay was calculated with the following Equation 5 drawn from $\mathrm{HCM}^{\text {th }}$ :

$d_{\text {approach }}=\frac{d_{l} \cdot v_{l}+d_{r} \cdot v_{r}}{v_{l}+v_{r}}$

where:

$d_{\text {approach }}$ - delay time at approach

$d_{l}, d_{r} \quad$ - delays for the left and right lanes.

$v_{l}, v_{r} \quad$ - entry flows for the left and right lanes.

The same O/D matrix shown in Table 3 is used in Aimsun ${ }^{\mathrm{TM}}$ simulations to obtain the delay. Three measures are used to determine goodness of fit:

- Root mean square percentile error (RMSPE)

$R M S P E=\sqrt{\frac{1}{n} \cdot \sum_{i=1}^{n}\left(\frac{x_{i}-y_{i}}{y_{i}}\right)^{2}}$

- Pearson's linear correlation coefficient $(r)$

$r=\frac{1}{n-1} \sum_{i=1}^{n} \frac{\left(x_{i}-\bar{x}\right)\left(y_{i}-\bar{y}\right)}{\sqrt{\sum_{i=1}^{n}\left(x_{i}-\bar{x}\right)^{2}} \sqrt{\sum_{i=1}^{n}\left(y_{i}-\bar{y}\right)}}$

- Theil's inequality coefficient $(U)$

$U=\frac{\sqrt{\frac{1}{n} \sum_{i=1}^{n}\left(y_{i}-x_{i}\right)^{2}}}{\sqrt{\frac{1}{n} \sum_{i=1}^{n} y_{i}^{2}} \sqrt{\frac{1}{n} \sum_{i=1}^{n} x_{i}^{2}}}$

The delays calculated with Equations 4 and 5 were compared with output delays from Aimsun ${ }^{\mathrm{TM}}$. The simulation model is consistent with the calculated values when all the three indices meet these threshold conditions: $R M S P E \leq 0.20, r \geq 0.80, U \leq 0.30$.

After setting the model parameters appropriately (i.e., simulation steps, reaction times, O/D matrix in Table 3), measures of goodness of fit are obtained (Table 1). 


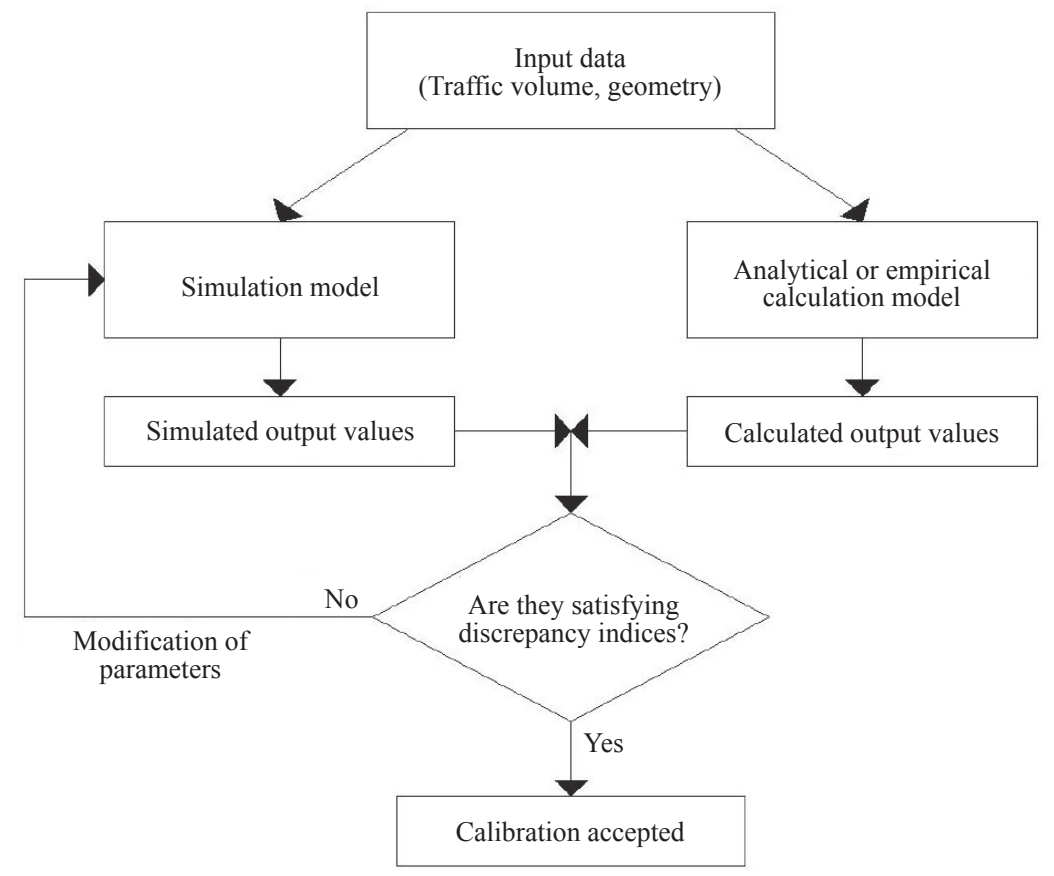

Figure 4 - Flowchart of the calibration process performed by Ainsum

Table 1 - Results of the comparison of output delays from Aimsun with delays calculated with Equations 4 and 5

\begin{tabular}{|c||c||}
\hline$R M S P E$ & 0.19 \\
\hline$r$ & 0.87 \\
\hline$U$ & 0.01 \\
\hline
\end{tabular}

It should be noted that the delay time values for low traffic volumes obtained with analytical and simulation models are similarly good approximations. In this case, there is no significant difference between the values of the calibrated parameters and the default values of Aimsun ${ }^{\mathrm{TM}}$.

\section{APPLICATION: VIA SCANSANESE, GROSSETO (ITALY)}

\subsection{Data collection and preparation}

The methodology (Figure 3) was applied to an existing road network, Provincial Road 159 - Via Scansanese, a two-lane arterial connecting the city center of Grosseto to Freeway E80 (Via Aurelia), at the Grosseto est-Centro interchange. This urban arterial is about $2 \mathrm{~km}$ long, and it is delimited by two intersections (Figures 6-7).

Intersection $\mathrm{A}$ is a single-lane double roundabout with irregular geometry and radii of 9.0 and 12.0 meters. Five roads converge at the intersection, and the widths and number of lanes of each are variables. Intersection $\mathrm{F}$ is an interchange of about 180

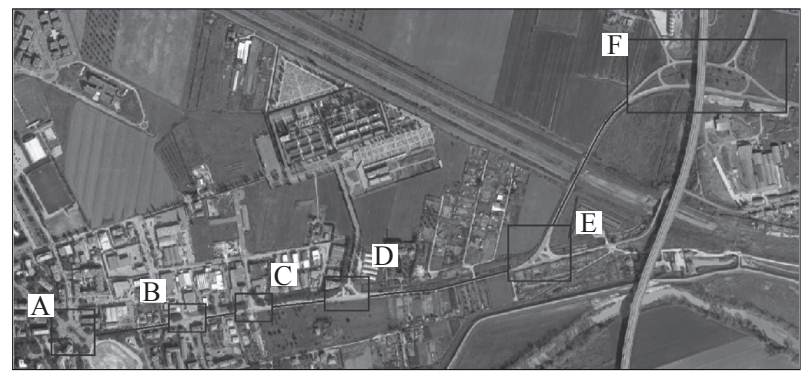

Figure 5-Map of the studied arterial and intersections - Via Scansanese (letters A-F)

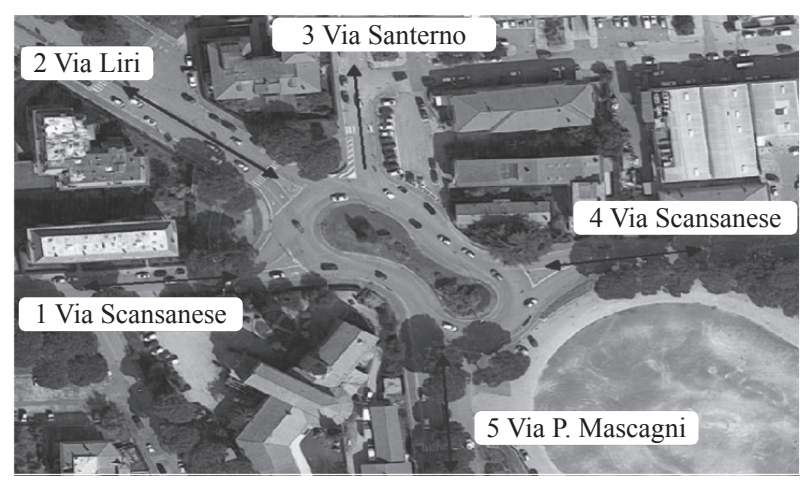

Figure 6-Intersection A

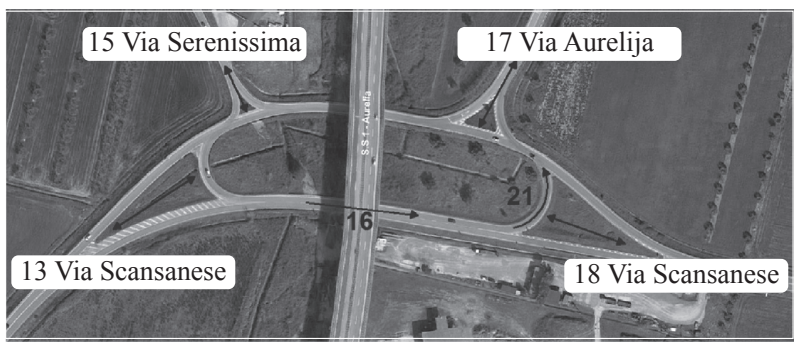

Figure 7 - Intersection $F$ 
meters east to west length and 7.5 meters of section width. From north to south, there are some intersections with approaches regulated by yield signs. In addition, the network has four other intersections, indicated by letters B through E (Figures 8-11).

Intersections $\mathrm{B}$ and $\mathrm{C}$ have 4 and 3 approaches, respectively, and are also regulated by yield control on the minor approaches. There are no auxiliary (turn or storage) lanes on the main arterial. Intersections $\mathrm{D}$ and $\mathrm{E}$ have 3 approaches each regulated by stop yield control on the minor approaches, but with storage lanes for turning off the main road.

Speed limits vary from 50 to $90 \mathrm{~km} / \mathrm{h}$ (31 and 56 $\mathrm{mph}$ ) for the different sections of the main road and from 30 to $50 \mathrm{~km} / \mathrm{h}$ (19 and $31 \mathrm{mph}$ ) for the secondary roads. Distances between the intersections are reported in Table 2.

Table 2 - Progressive distances between intersections of the study network

\begin{tabular}{||c|c||}
\hline Intersections & Distance $[\mathrm{m}]$ \\
\hline \hline A-B & 261.70 \\
\hline B-C & 173.55 \\
\hline C-D & 237.80 \\
\hline D-E & 362.10 \\
\hline E-F & 642.30 \\
\hline
\end{tabular}

The traffic flows were derived both from the Traffic Master Plan (2010), drawn up by the City of Grosseto, and by estimating the distribution of the volumes of turning traffic. The study time was set to the AM peak hour (7:45 to $8: 45$ ) on weekdays.

The O/D matrices were derived for each intersection (Table 3) and the Equation 4 or Equation 5 was used to estimate the delay for each entry lane, which was compared with those determined by Aimsun ${ }^{\mathrm{TM}}$. Table 4 is a summary of the obtained results.

\subsection{Results}

The average speed-time diagrams of the approaches to the various intersections were obtained from the simulation trials, with related values of resilience index $R I$ computed by Equation 3. The least acceptable value for $R I$ is 0.70 : for the intersections having a $R I<0.7$, design changes have been proposed. The $R I$ value has been calculated from

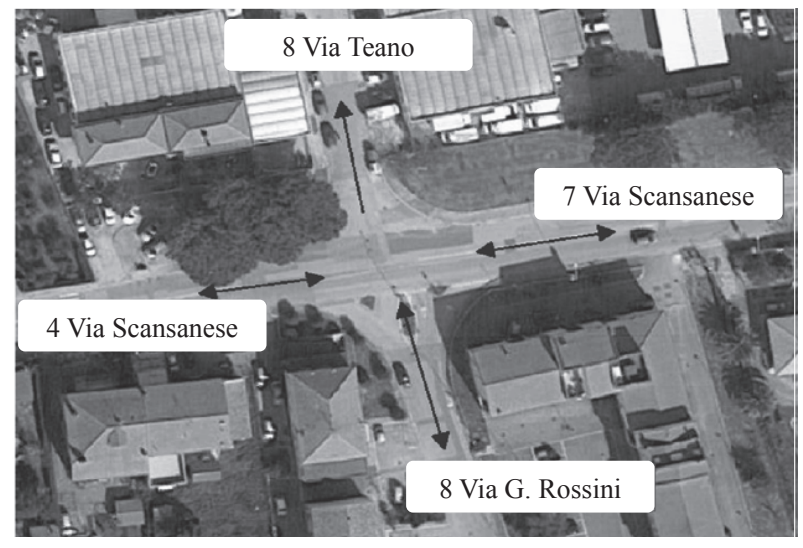

Figure 8-Intersection B

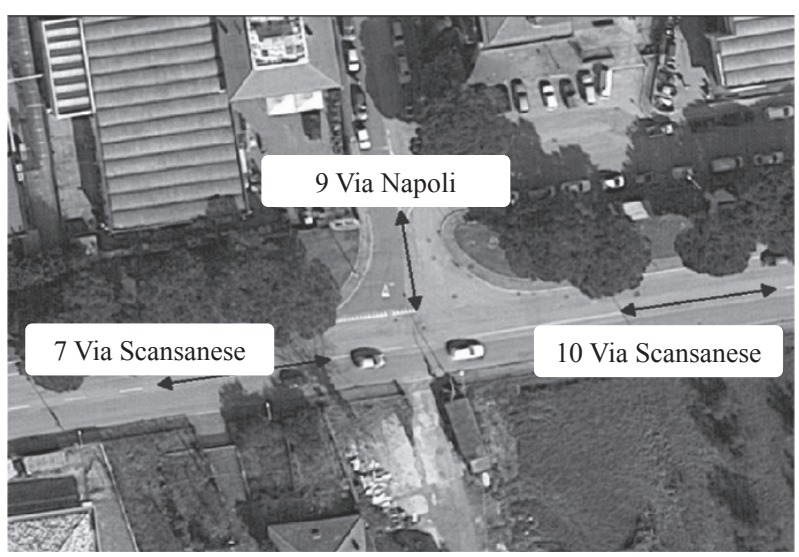

Figure 9 - Intersection C

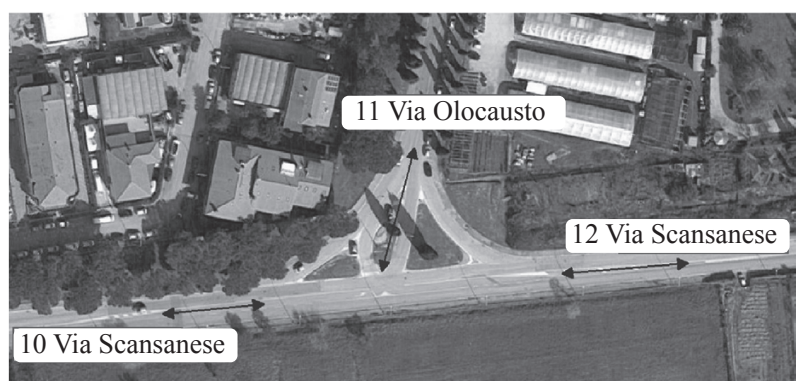

Figure 10 - Intersection D

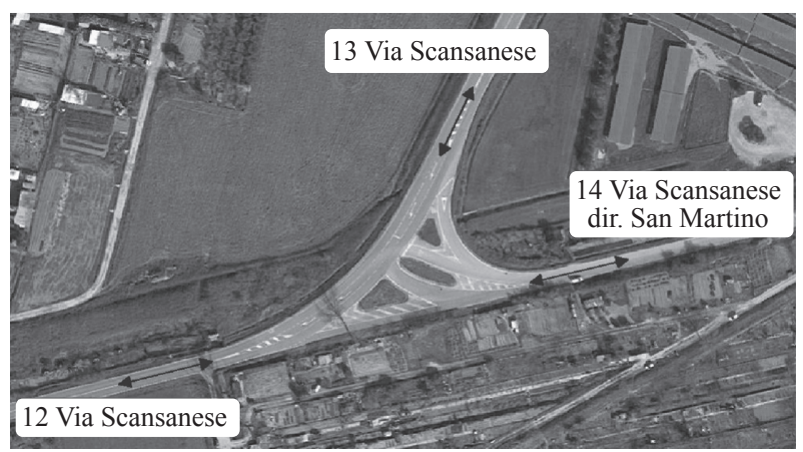

Figure 11 - Intersection E

Equation 3; $v^{*}$ varies from one intersection to another, in the case of the intersection $\mathrm{A}$ it is equal to 40 $\mathrm{km} / \mathrm{h}$. 
Pratelli A, Leandri P, Aiello R, Souleyrette RR. Intersection Redesign for Network Resilience and Safety

Table 3 - O/D matrices of the network intersections [pce/h]

\begin{tabular}{|r|r|r|r|r|r|}
\hline \multicolumn{7}{|c|}{ Intersection A-Matrix O/D } \\
\hline$i / j$ & 1 & 2 & 3 & \multicolumn{1}{c|}{4} & \multicolumn{1}{c|}{5} \\
\hline 1 & 0 & 112 & 64 & 65 & 80 \\
\hline 2 & 89 & 0 & 100 & 102 & 126 \\
\hline 3 & 0 & 0 & 0 & 0 & 0 \\
\hline 4 & 189 & 369 & 210 & 0 & 266 \\
\hline 5 & 228 & 446 & 382 & 258 & 0 \\
\hline
\end{tabular}

\begin{tabular}{|r|r|r|r|r|}
\hline \multicolumn{5}{|c|}{ Intersection B-Matrix O/D } \\
\hline$i / j$ & \multicolumn{1}{|c|}{4} & \multicolumn{1}{c|}{6} & \multicolumn{1}{c|}{7} & \multicolumn{1}{c|}{8} \\
\hline 4 & 0 & 42 & 376 & 5 \\
\hline 6 & 0 & 0 & 0 & 0 \\
\hline 7 & 1,002 & 63 & 0 & 7 \\
\hline 8 & 25 & 2 & 14 & 0 \\
\hline
\end{tabular}

\begin{tabular}{|r|r|r|r|}
\hline \multicolumn{5}{|c|}{ Intersection C-Matrix O/D } \\
\hline$i / j$ & \multicolumn{1}{c|}{7} & \multicolumn{1}{c|}{9} & \multicolumn{1}{c|}{10} \\
\hline 7 & 0 & 83 & 295 \\
\hline 9 & 78 & 0 & 48 \\
\hline 10 & 994 & 172 & 0 \\
\hline
\end{tabular}

\begin{tabular}{|r|r|r|r|}
\hline \multicolumn{4}{|c|}{ Intersection D-Matrix O/D } \\
\hline$i / j$ & \multicolumn{1}{|c|}{10} & \multicolumn{1}{c|}{11} & \multicolumn{1}{c|}{12} \\
\hline 10 & 0 & 14 & 329 \\
\hline 11 & 10 & 0 & 3 \\
\hline 12 & 1,144 & 12 & 0 \\
\hline
\end{tabular}

\begin{tabular}{|r|r|r|r|}
\hline \multicolumn{4}{|c|}{ Intersection E-Matrix O/D } \\
\hline$i / j$ & 12 & 13 & \multicolumn{1}{c|}{14} \\
\hline 12 & 0 & 313 & 9 \\
\hline 13 & 1000 & 0 & 18 \\
\hline 14 & 155 & 101 & 0 \\
\hline
\end{tabular}

\begin{tabular}{|r|r|r|r|r|}
\hline \multicolumn{5}{|c|}{ Intersection F-Matrix O/D } \\
\hline$i / j$ & 13 & 15 & \multicolumn{1}{c|}{17} & \multicolumn{1}{c|}{18} \\
\hline 13 & 0 & 85 & 326 & 7 \\
\hline 15 & 220 & 0 & 216 & 5 \\
\hline 17 & 678 & 174 & 0 & 15 \\
\hline 18 & 115 & 30 & 113 & 0 \\
\hline
\end{tabular}

Table 4 - Static values and simulation outputs

\begin{tabular}{||c||c|c|c|c|c||}
\hline Entry & 1 & 8 & 9 & 14 & 17 \\
\hline \multicolumn{7}{|c||}{ Values from static equations } \\
\hline $\begin{array}{c}\text { Delay } \\
{[\mathrm{s} / \text { pce }]}\end{array}$ & 11.20 & 11.68 & 12.31 & 12.47 & 17.09 \\
\hline \multicolumn{7}{|c||}{ Output from Aimsun } & \\
\hline $\begin{array}{c}\text { DM } \\
{[\mathrm{s} / \text { pce }]}\end{array}$ & 6.67 & 10.25 & 12.10 & 12.54 & 16.28 \\
\hline
\end{tabular}

Table 5 - Resilience index values of intersection $A$

\begin{tabular}{||c||c|c|c|c||}
\hline Entry & 1 & 2 & 4 & 5 \\
\hline$R I$ & 0.70 & 0.81 & 0.25 & 0.32 \\
\hline $\begin{array}{c}\text { LOR }[\mathrm{km} / \\
\mathrm{h} \cdot \mathrm{min}]\end{array}$ & 1069.95 & 668.10 & 2667.60 & 2403.60 \\
\hline \multicolumn{5}{|c||}{ Intersection A } \\
\hline$R I$ & 0.40 \\
\hline
\end{tabular}

By studying the individual average speed-time profiles, the critical approaches that penalize the intersections in question can be identified, in order to predict a single local intervention in the specific approach rather than a global one. Figure 12 shows the diagrams relating to intersection A with the approach RIs indicated. Approaches 4 and 5 are the most heavily loaded and have greater loss of resilience. Table 5 presents $R I$ and $L O R$ values for of intersection A. Note that there is no information for approach 3 as it is a one-way flow only out of the intersection. Figure 13 presents the results for all intersections of the road network. From these, the network resilience index (arithmetic mean) is computed as RInetwork $=0.62$.

The traffic flows in via Scansanese in the period under consideration are about $1000 \mathrm{pce} / \mathrm{h}$ towards the Grosseto city center and about $500 \mathrm{pce} / \mathrm{h}$ in the opposite direction. The most critical intersection is intersection A, in which Via Scansanese crosses via Liri and via Mascagni, which are important arterials of the city in the north-south direction. The traffic flow in approach 4 (Via Scansanese towards city center) is equal to nearly $1000 \mathrm{pce} / \mathrm{h}$, while in approach 5 (via Mascagni, direction north) it is about $1250 \mathrm{pce} / \mathrm{h}$. These approaches have a flow to baseline capacity ratio over $90 \%$, and this explains why the speed decreases so sharply in case of a disruptive event.

The resilience of the entire segment can be determined by introducing a third dimension to the measurement of resilience, namely: space. Accordingly, by using a three-dimensional model, it is possible to observe how the performance changes, both with respect to time and along the different sections of the network [7]. Therefore, the resilience index is not defined as the ratio between two surfaces but as the ratio between two volumes. In this paper, network optimization was achieved by intervening on 


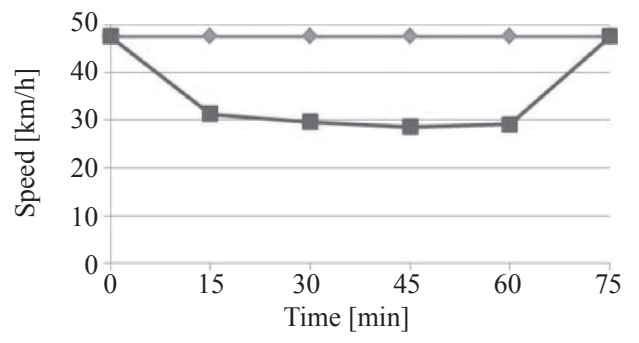

a) Approach 1

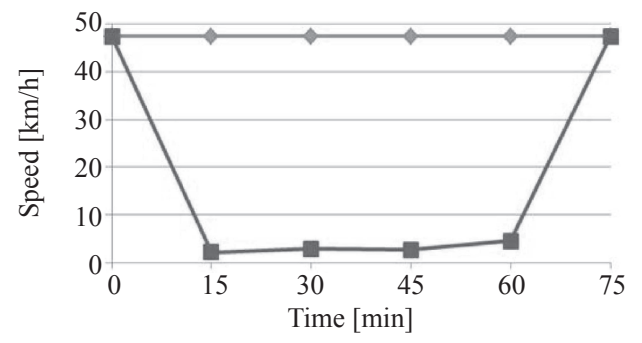

c) Approach 4

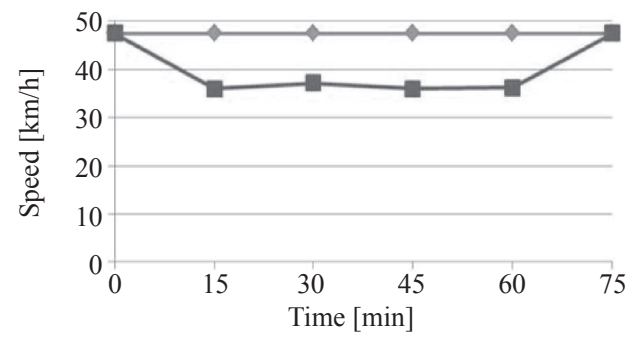

b) Approach 2

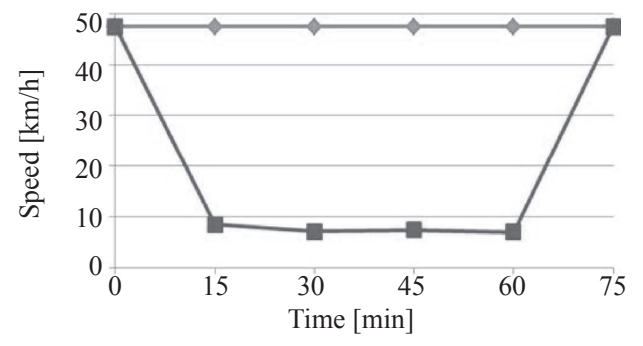

d) Approach 5

Figure 12 - Average speed-time diagrams of the approaches of intersection A

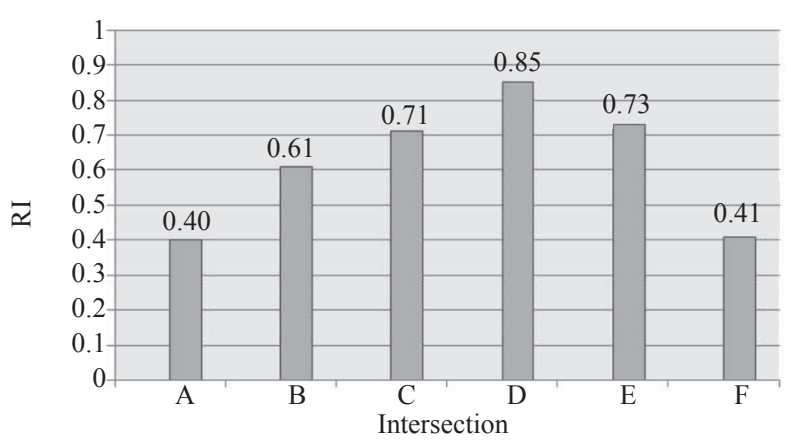

Figure 13 - Resilience index, RI, values of the study network intersections

the intersections, therefore a two-dimensional analysis was considered sufficient and adequate. However, these two dimensions alone do not reflect the effective continuous nature of the road, as performance not only varies over time but also along the network [7].

\section{SUGGESTIONS FOR MODIFICATIONS OF INTERSECTIONS}

Following a previous instance explored by Pratelli et al. [11], a simulation-based method was applied to improve safety and efficiency by redesigning the layout of some of the existing roundabouts and intersections.

From Figure 13, the most critical intersections are $\mathrm{A}, \mathrm{B}$ and $\mathrm{F}$. Intersection A is space constrained, but can be adjusted by increasing the radii of the two roundabout circumferences in order to add two entry lanes for approach 4 (i.e., Via Scansanese) and widen the entry for approach 5 (i.e., Via Mascagni in Figure 14). Local action was taken on the two most unfavorable approaches, namely with lower RI.

For intersection $\mathrm{B}$, a new roundabout with a diameter of 28 meters was suggested with two entry lanes for the branches of the main road Via Scansanese. With this new configuration, the conflict points in the present design will be reduced (Figure 15). For intersection $\mathrm{F}$, two twin roundabouts with a diameter of 50 meters with two entry lanes at the branches of Via Scansanese and Via Aurelia (the "Grosseto est-Centro" exit) are suggested where the entrance to Via Serenissima could be enlarged. With this new configuration, the weaving section will be eliminated (Figure 16).

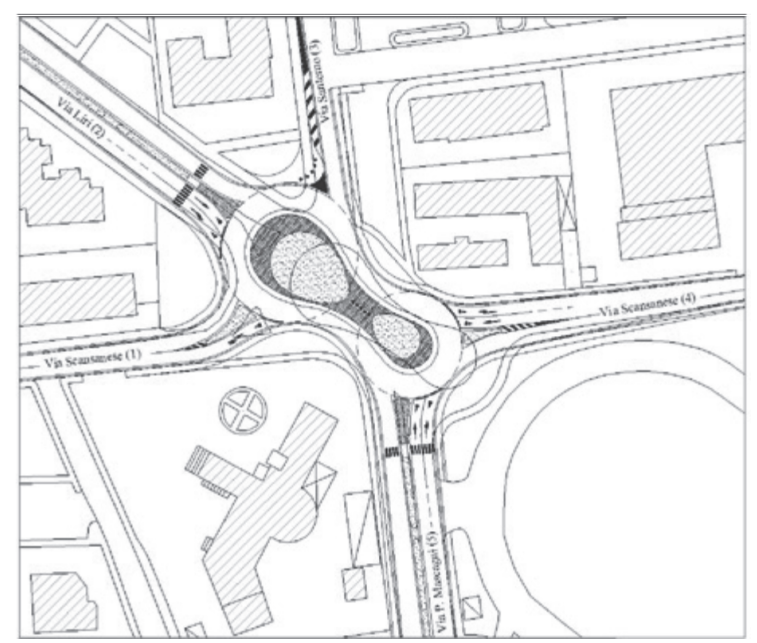

Figure 14 - Intersection A, changed state 


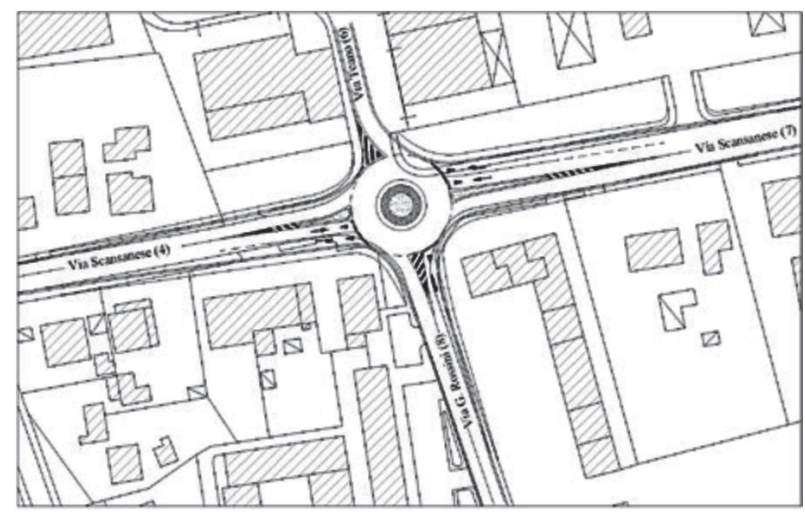

Figure 15 - Intersection B, changed state

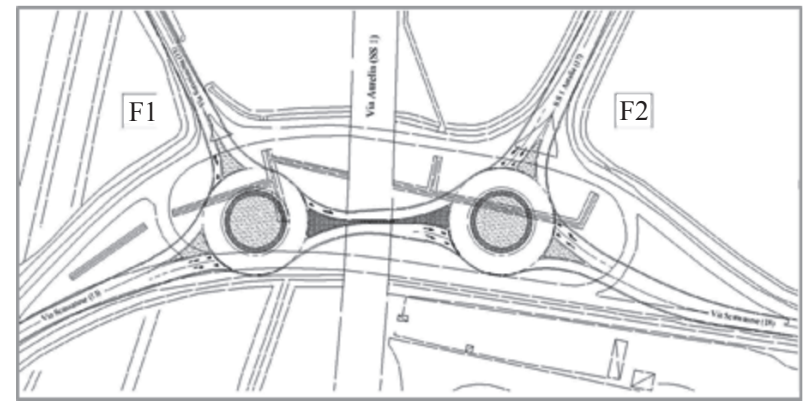

Figure 16-Intersection F, changed state Figure $16-$ Intersection $F$, changed state

The suggested network with its redesigned intersections has been modeled on Aimsun ${ }^{\mathrm{TM}}$. No changes have been made to the calibration achieved with the present state and traffic conditions; Figure 17 depicts the new results.

Comparing the values obtained from the present state (Figure 13) with those of the modified state (Figure 17), it is observed that the RI increases in the intersections where a change has been made, while in the remaining intersections the resilience remains almost unchanged. The new network resilience index is computed as RInetwork $=0.68$, representing an increase of about $10 \%$ in resilience. The design solutions presented provide the road network with a

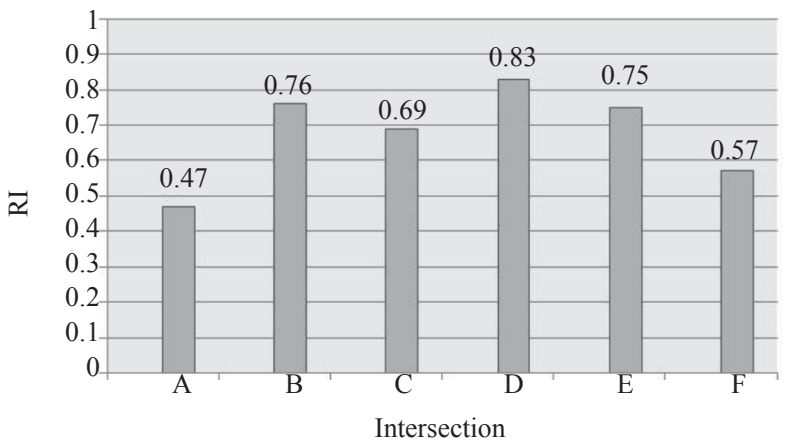

Figure 17 - Resilience index values of the intersections of study network (changed state) more robust and rapid response, thereby decreasing the possibility of it becoming unstable when other different disturbing events occur.

\section{SAFETY OF INTERSECTION B}

Safety is a critical concern at roadway intersections, and the redesign changes that promote resilience can at the same time improve safety. Therefore, intersection B of the network has been evaluated for safety performance, both in the present and redesigned states. Through Aimsun ${ }^{\mathrm{TM}}$ it was possible to model safety by hypothesizing two different scenarios, both on the main street Via Scansanese and in the two opposite directions. The duration of an event starting at 8:00 a.m. was set to 30 minutes, the time assumed to remove vehicles involved. Such a situation was simulated for each entrance approach. Consequently, the average speed-time diagram and the corresponding resilience indices were evaluated with respect to the $A P$ curve of the present state according to the equation:

$$
R I=\frac{\int_{t_{0}}^{t_{2}} A P(t) d t}{\int_{t_{0}}^{t_{2}} T P(t) d t}=\frac{\int_{t_{0}}^{t_{2}} T P(t) d t-L O R}{\int_{t_{0}}^{t_{2}} T P(t) d t}=1-\frac{L O R}{\int_{t_{0}}^{t_{2}} T P(t) d t}
$$

where $\int_{t_{0}}^{t_{2}} T P(t) d t$ is the surface underlying the $A P$ curve under normal traffic flow conditions in the current design.

The loss of resilience, or $L O R$, is obtained from the Aimsun ${ }^{\mathrm{TM}}$ outputs relating to the incident model. The type of conflict considered is that which occurs between the vehicles queuing on the entrance approaches.

The first "section accident" has been applied to the approach of Via Scansanese at the entrance to intersection B towards Via Aurelia (approach 4 in Figure 18). In the changed state, the accident was simulated only in the left lane. The results are shown in Table 6.

The second "section accident" has been applied to the approach of Via Scansanese at the entrance to intersection B towards the Centre of Grosseto (approach 7 in Figure 19). In the changed state, the accident was simulated only in the left lane. The obtained results are reported in Table 7. 


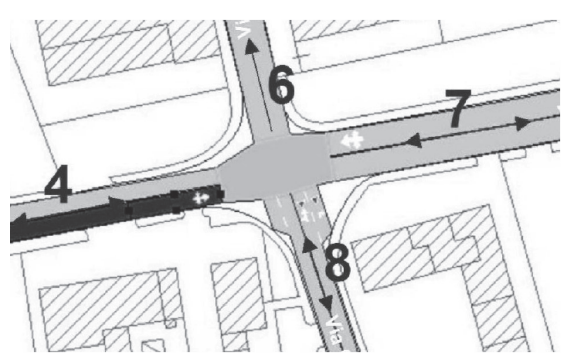

Current state

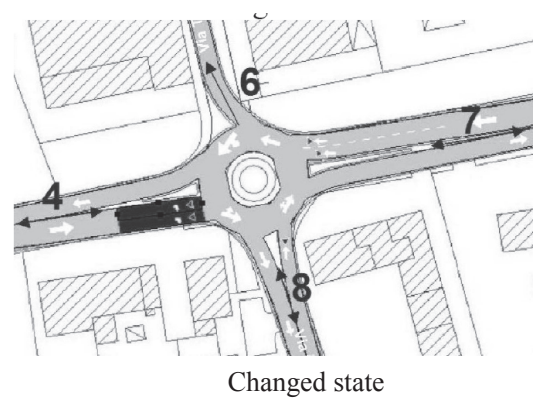

Changed state

Figure 18 - Scenario \#incident 1
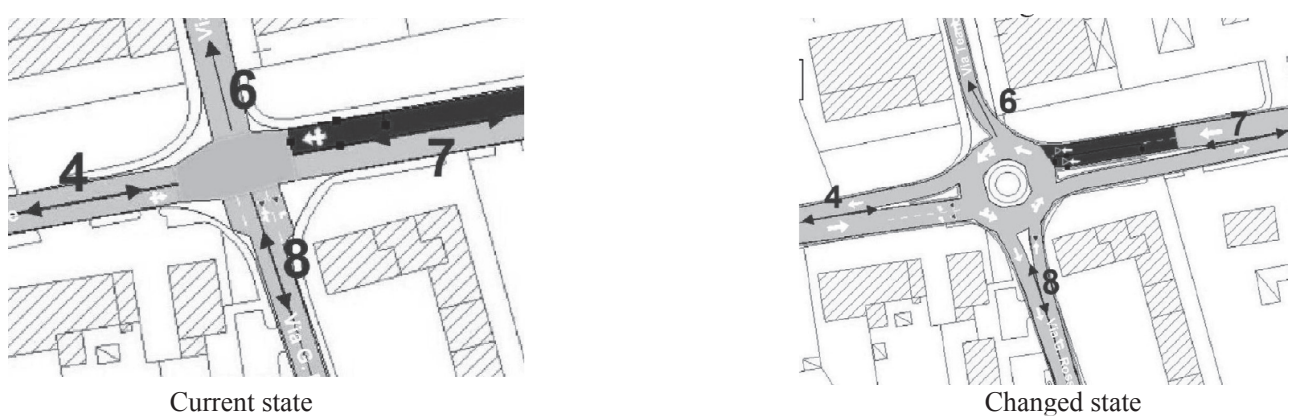

Figure 19 - Scenario \#incident 2

Table 6 - Resilience index values of the intersection $B$ Scenario \#incident 1 a

\begin{tabular}{|c|c|c|c|}
\hline Entry & 4 & 7 & 8 \\
\hline \multicolumn{4}{|c|}{ Current state } \\
\hline$R I$ & 0.47 & 0.48 & 0.79 \\
\hline $\begin{array}{c}L O R \\
{[\mathrm{~km} / \mathrm{h} \cdot \mathrm{min}]}\end{array}$ & 1737.75 & 281.90 & 163.67 \\
\hline \multicolumn{4}{|c|}{ Intersection B } \\
\hline$R I$ & \multicolumn{3}{|c|}{0.50} \\
\hline \multicolumn{4}{|c|}{ Changed state } \\
\hline$R I$ & 0.74 & 0.71 & 0.81 \\
\hline $\begin{array}{c}L O R \\
{[\mathrm{~km} / \mathrm{h} \cdot \mathrm{min}]}\end{array}$ & 180.52 & 19.52 & 50.90 \\
\hline \multicolumn{4}{|c|}{ Intersection B } \\
\hline$R I$ & & 0.75 & \\
\hline
\end{tabular}

Table 7 - Resilience index values of the intersection B_Scenario \#incident 2

\begin{tabular}{||c||c|c|c||}
\hline Entry & 4 & 7 & 8 \\
\hline \multicolumn{4}{|c||}{ Current state } \\
\hline$R I$ & 0.96 & 0.38 & 0.85 \\
\hline $\begin{array}{c}L O R \\
{[\mathrm{~km} / \mathrm{h} \cdot \mathrm{min}]}\end{array}$ & 11.46 & 695.70 & 35.83 \\
\hline \multicolumn{4}{|c||}{ Intersection B } \\
\hline$R I$ & \multicolumn{4}{|c||}{0.41} \\
\hline \multicolumn{4}{|c||}{ Changed state } \\
\hline$R I$ & 0.79 & 0.67 & 0.81 \\
\hline $\begin{array}{c}L O R \\
{[\mathrm{~km} / \mathrm{h} \cdot \mathrm{min}]}\end{array}$ & 0.00 & 216.36 & 35.10 \\
\hline \multicolumn{4}{|c||}{ Intersection B } \\
\hline$R I$ & \multicolumn{3}{|c||}{0.69} \\
\hline
\end{tabular}

In both scenarios, in the current state, the closure of one lane following the impediment causes a high loss of resilience (LOR) in the approach and the formation of long queues, the effects of which are felt in the near intersections because of the short distance; while in the changed state, closing the left lane does not cause the interruption of the vehicle flow since the vehicles use the adjacent lane to overcome the obstacle, so long queues do not form. Also the LOR of the approach is contained.

\section{CONCLUSION}

This paper describes a procedure for improving the resilience of roadway networks. The loss of resilience (LOR), which occurs from the moment the disaster begins until the system performance has completely recovered, is used to quantify resilience, and it is defined according to the quality of the system over time.

The Resilience Index (RI) could be defined as the ratio between the integrals of the Actual Performance (AP) and of the Target Performance (TP) curves. The AP represents the system under the disrupted condition, while the TP is the curve that represents the system performance under normal conditions or a pre-established performance standard. The Resilience Index varies between 0 and 1 . An RI equal to 1 indicates a 100 percent resilient system, and it approaches 0 when LOR values are 
high. The paper has described a methodology to identify critical intersections in order to optimize the network in terms of resilience under normal traffic conditions. The urban arterial considered in this study was the Via Scansanese, the road connecting the city of Grosseto (Italy) to Freeway E80, consisting of six intersections. By using a calibrated Aimsun ${ }^{\mathrm{TM}}$ micro-simulation model, it was possible to determine the $R I$ index of each intersection in the network.

Design changes have been suggested and evaluated for intersections with $R I<0.70$, (new and modified roundabouts). The most critical intersections have resulted with $\mathrm{A}, \mathrm{B}$ and $\mathrm{F}$, showing an RI equal to $0.40,0.61$, and 0.41 , respectively. The geometry and performance characteristics of such intersections have been radically improved in the simulation.

The intersection A is currently a roundabout, and its geometry has been improved, but some space constraints exist, therefore a radical increase in performance was not possible. The intersection $\mathrm{B}$, which is currently an unsignalized intersection, has been converted into a roundabout. The intersection $\mathrm{F}$ has instead been converted into two separate roundabouts. After such improvements, the RI of the intersections $\mathrm{A}, \mathrm{B}$ and $\mathrm{F}$ has been increased to $0.47,0.76$ and 0.57 , respectively. It was also determined that road safety was improved by redesigning some network intersections for improved resilience, thereby providing a double benefit for road investment: this is the case of the intersection B. By using the simulation model of Aimsun ${ }^{\mathrm{TM}}$, it was possible to determine the increase of resilience following some improvement interventions on the network. This modelization has been applied to an arterial in Grosseto but can be extended to any congested urban network.

Finally, within the limits of the experimental results obtained, the analysis highlighted that roundabouts are more robust than other types of intersection, restoring their performance quickly and effectively in case of loss of resilience due to a disturbing event that occurred in a road network.

ANTONIO PRATELLI, M.S. ${ }^{1}$

E-mail: antonio.pratelli@ing.unipi.it

PIETRO LEANDRI, M.S. ${ }^{1}$

E-mail: pietro.leandri@ing.unipi.it

ROSARIA AIELLO, M.S. ${ }^{1}$

E-mail: aiello.sara91@gmail.com

REGINALD R. SOULEYRETTE, Ph.D. ${ }^{2}$

E-mail: souleyrette@uky.edu
${ }^{1}$ Università di Pisa

Dipartimento di Ingegneria Civile e Industriale

Largo Lucio Lazzarino 2, 56122 Pisa, Italia

2 University of Kentucky

Department of Civil Engineering

Oliver H. Raymond Civil Engineering Building 161A,

40506 Lexington - KY, U.S.A.

\section{PROGETTAZIONE DEI NODI DI INCROCIO \\ PER UNA RETE STRADALE CON ADEGUATE \\ CARATTERISTCHE DI SICUREZZA E \\ RESILIENZA}

\section{SINTESI}

Uno degli aspetti per aumentare la resilienza di una rete viaria è lo sviluppo di una metodologia capace di identificare le criticità e valutare i miglioramenti conseguenti ad una modifica apportata. L'articolo descrive una procedura che include l'utilizzo di un indice, basato sui dati di traffico e sull'andamento nel tempo delle prestazioni del sistema, per misurare la resilienza di un'arteria stradale soggetta a problemi di congestione. Tale schema è stato applicato a una strada italiana a sud della toscana, con l'obiettivo di andare ad ottimizzare, in termini di resilienza, le intersezioni che risultano critiche a causa di una inadeguata capacità di base delle stesse. La metodologia prevede la creazione di un modello dinamico di simulazione il quale è stato opportunamente calibrato attraverso il calcolo dei tempi medi di attesa alle entrate di alcuni approcci della rete, che sono stati stimati con un modello analitico (formule Highway Capacity Manual 2016). Dalla simulazione si è ottenuto, per ogni ramo in ingresso negli attraversamenti, $i$ valori delle velocità medie nel tempo. Questo set di valori è utilizzato come input per il calcolo dell'indice di resilienza ai nodi. In questo modo la procedura permette di individuare le intersezioni meno resilienti, e di prevedere per esse delle soluzioni progettuali al fine di ottenere una rete più resiliente sotto le normali condizioni di traffico. Gli interventi proposti fanno riferimento alla trasformazione di attraversamenti a raso semplici in rotatorie e all'adeguamento di rotatorie esistenti. Infine è stata analizzata una delle intersezioni della rete sotto una diversa condizione di criticità (incidenti stradali), sia nello stato attuale sia nello stato di progetto, allo scopo di studiare gli effetti della modifica apportata. La procedura è stata applicata usando il software Aimsun ${ }^{\mathrm{TM}}$.

\section{PAROLE CHIAVE}

resilienza; resilienza delle reti stradali; indice e scala di resilienza di una rete viaria; simulazione dinamica del traffico in una rete stradale urbana.

\section{REFERENCES}

[1] Ouyang M, Dueñas-Osorio L, Min X. A three-stage resilience analysis framework for urban infrastructure 
systems. Structural Safety. 2012;36-37: 23-31.

[2] Tierney K, Bruneau M. Conceptualizing and measuring resilience: A key to disaster loss reduction. TR News. 2007;250: 14-17.

[3] [3] Maestrelli Leobons C, Barcellos Gouvêa Campos V, DeMello Bandeira A. Assessing urban transportation systems resilience: A proposal of indicators. Transportation Research Procedia. 2019;37: 322-329.

[4] Zhou Y, Wang J, Yang H. Resilience of transportation systems: Concepts and comprehensive review. IEEE Transactions on Intelligent Transportation Systems. 2019;20(12): 4262-4276.

[5] Bruneau M, Chang SE, Eguchi RT, Lee GC, O'Rourke T, Reinhorn AM, Von Winterfeldt D. A framework to quantitatively assess and enhance the seismic resilience of communities. Earthquake Spectra. 2003;19(4): 733-752.

[6] Balal E, Valdez G, Miramontes J. Comparative evaluation of measures for urban highway network resilience due to traffic incidents. International Journal of Transportation Science and Technology. 2019;8(3): 304-317.
DOI: 10.1016/j.ijtst.2019.05.001

[7] Nieves-Meléndez ME. Traffic-based framework for measuring the resilience of ground transportation systems under normal and extreme conditions. $\mathrm{PhD}$ thesis. Virginia Polytechnic Institute and State University; 2017. Available from: vtechworks.lib.vt.edu > handle > Nieves-Melendez_ME_D_2017

[8] Nieves-Meléndez ME, De la Garza JM. Resilience frameworks instantiated to vehicular traffic applications. Sustainable and Resilient Infrastructure. 2017;2(2): 75-85.

[9] FHWA. Traffic congestion and reliability: Trends and advanced strategies for congestion mitigation. Cambridge Systematics Inc. Final Report, 2005.

[10] TRB. Performance measurement framework for highway capacity decision. SHRP 2 Report S2-C02-RR, 2009.

[11] Pratelli A, Sechi P, Souleyrette RR. Upgrading traffic circles to modern roundabouts to improve safety and efficiency - Case Studies from Italy. Promet - Traffic \&Transportation. 2018;3: 217-29. 